\title{
The role of awareness in the operant conditioning of eye blinks
}

\author{
FARILYN JONES and LARRY HOCHHAUS \\ Oklahoma State University, Stillwater, Oklahoma 74074
}

\begin{abstract}
The present study is concerned with the problem of awareness in the operant conditioning of a nonverbal behavior, eye blinks. Using a within-subjects design, 14 subjects' blink rates were counted and compared for four periods of $4 \mathrm{~min}$ each. The experimenter and the subject carried on an informal conversation during both base and reinforcement periods, but during reinforcement periods only, a light flashed on immediately after each of the subject's blinks. The test for awareness consisted of brief questioning after reinforcement periods and a more extensive postexperimental interview. Only data for the eight unaware subjects were used in statistical analysis. A two-factor analysis of variance showed no evidence of conditioning without awareness; in fact, the blink rate for reinforcement periods was significantly less than the rate for base periods $(p<.05)$. The anomaly was explained in terms of the effects of cognitive activity on eye-blink rate.
\end{abstract}

Much of the research concerning eye blinks has focused on the physiological aspects of blinking or on various factors which may affect blink rate: Ponder and Kennedy (1927), in their thorough and comprehensive review of various aspects of blinking, proposed that emotional and cognitive mental states are more important in affecting blink rate than most emotional factors. For example, anxiety is associated with high blink rates and intense cognitive activity with low blink rates. Holland and Tarlow (1972) similarly report differential rates of blinking for different mental states. Hall (1945) conducted a series of experiments on eye blinks, and he discussed the variety and purposes of blinks in man. Blink rate has been found to vary with type of task (Hall, 1945) and with the difficulty of the task (Luckiesh, 1947).

In the area of classical conditioning, extensive research has been conducted on the conditioning of the reflex blink (e.g., Spence, 1956). There seems a lack of research, however, in the area of operant conditioning of eye blinks. This is surprising, since eye blinks appear to be an ideal behavior for operant experimentation. Eye blinks are quite public and are highly discrete; therefore, they are easy to observe and.count. Additionally, blinks have a high operant rate and are certain to occur fairly often. Because blinks are ideal for operant experimentation and because research seems lacking in the area, the present investigation in operant conditioning used eye blinks as the response to be conditioned.

One issue which has arisen in the area of operant conditioning and which has generated much controversy is the problem of "awareness" in operant conditioning. Awareness is usually defined as the ability of a subject

This research was supported in part by a grant from the State of Oklahoma. Requests for reprints should be addressed to Larry Hochhaus, Department of Psychology, Oklahoma State University, Stillwater, Oklahoma 74074. to verbalize a correct response-reinforcement contingency (e.g., Krasner, 1958). The awareness problem asks whether the nature of the subject's awareness of the situation helps determine the learning outcome.

The awareness issue has been particularly debated in the field of verbal conditioning. In a study by Greenspoon (1955), a conditioning effect apparently occurred without the subjects being aware of the reinforcement contingency. Yet certain critics of the conditioning without awareness position, including DeNike (1964) and Dulany (1961), have presented substantial evidence that conditioning results only if the subjects are, in fact, "aware." In spite of the apparent closure that has been achieved regarding verbal conditioning, there seems to be need for further research on awareness in the area of nonverbal operant conditioning. The present study is concerned with the problem of awareness in the conditioning of a nonverbal behavior, eye blinks. It was hypothesized that, with the use of appropriate measures of awareness, the conditioning of eye blinks does not occur if the subject is unaware of the responsereinforcement contingency.

\section{METHOD}

\section{Subjects}

The subjects were 15 undergraduate volunteers, eight females and seven males. All subjects were enrolled in an introductory general psychology course at Oklahoma State University, and all received extra course credit for their participation. The data for one male subject had to be discarded due to an equipment malfunction; this left a total of 14 subjects.

\footnotetext{
Apparatus

The frequency of eye blinks was recorded via a silent hand-held thumb switch which triggered a counter in an adjacent room. The experimenter observed the subject constantly during all four periods and pressed the switch after each of the subject's blinks. Before reinforcement periods, the experimenter additionally connected the switch to a light panel which faced the
} 


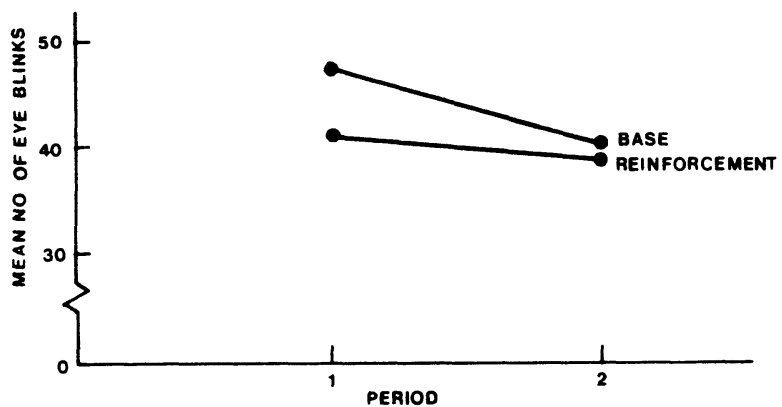

Figure 1. Mean number of eye blinks for base and reinforcement periods.

subject. Thus, the light flashed immediately following each eye blink and, simultaneously, the counter advanced. The experimenter used a stopwatch to time each 4-min period.

\section{Design}

The dependent variable was the frequency of eye blinks, and the independent variable was a momentary flash of the light immediately following each eye blink. A light has been shown to be an effective reinforcer by both Greenspoon (Note 1) and Sidowski (1954).

One variable which was not controlled in the experiment was the wearing of contact lenses. It was assumed that, although wearing contacts may affect a subject's blink rate, it should not affect the blink rate differentially in reinforcement and control periods: The effect was expected to balance out over the periods.

The experiment was divided into four periods, each of 4-min duration. The design used was the within-subjects design. The subjects' blink rates were compared for the four periods-two base periods and two experimental periods when the reinforcement was presented. The order of the periods was counterbalanced: Half of the subjects had a base-reinforcement-basereinforcement sequence of periods, and the other subjects had a reinforcement-base-reinforcement-base sequence. Subjects were randomly assigned to a sequence.

A two-factor analysis of variance was used in the treatment of the data. One factor compared the base and reinforcement periods and the other factor compared phases. Phase 1 consisted of the first base period $\left(B_{1}\right)$ and the first reinforcement period $\left(R_{1}\right)$, while Phase 2 consisted of $B_{2}$ and $R_{2}$. The factorial analysis was used to determine if there was a significant difference: (1) between the base and reinforcement periods; (2) between the phases, which would indicate a trend in blink rate; and (3) to indicate any interaction between time and the experimental conditions.

\section{Procedure}

The subject, seated at one end of a small table, faced the light panel at the other end of the table. The experimenter was seated across from the subject so that the subject's eye blinks could be counted easily. The experimenter read the following instructions: "This is an experiment in operant conditioning, and it consists of four four-minute periods. During this time, you and I will be carrying on an informal conversation, and I may ask you a few questions. During two of the periods only, a light on this panel [experimenter points to light] will blink on following each occurrence of a particular behavior of yours. Your task is to make the light come on as frequently as possible. At the end of a period, I will ask you if you know what behavior made the light come on. Please tell me any ideas you may have about it at that time. Although the light will not be flashing on during two of the periods, it is important that you focus your gaze in the general vicinity of the light during all periods. [The purpose of gazing at the light at all times was to prevent subjects from looking around the room, thus making it difficult to count blinks.] Do you have any questions about the procedure? Before we start, let me remind you to try to make the light come on as of ten as possible."

After reading the instructions, the experimenter either connected or disconnected the light, depending on the sequence of the $B_{1}$ and $R_{1}$ periods. The experimenter then informed the subject whether the light would be coming on during the first period. At this point, the experimenter started the stopwatch and began to engage in an informal conversation with the subject. Some general topics for conversation were the weather, subject's year in school, subject's major and vocational plans, subject's hometown, recent vacations, subject's psychology class, other college courses, recent movies, etc. The reason for using informal conversation rather than a more rigid and controlled activity can be justified at this time. In a pilot study, 12 subjects listened to a tape during all four periods. All subjects became aware of the reinforcement contingency almost immediately, because the range of subjects' responses was restricted to only a few behaviors. During conversation, however, the subject engages in a variety of verbal and nonverbal behaviors other than eye blinks. Thus, conversation made it more difficult, though certainly not impossible, to become aware of the responsereinforcement contingency.

As the experimenter and subject conversed, the experimenter held the thumb switch in her lap under the edge of the table so that the subject could not detect the counting. During a base period, the experimenter just counted the number of eye blinks, but in a reinforcement period, the experimenter counted, and simultaneously flashed the light immediately after each of the subject's blinks. At the end of the period, the experimenter informed the subject that it was the end of the first period. If it was a reinforcement period, the experimenter asked, "What do you think made the light come on?" If a subject correctly stated that blinks made the light come on, the experiment was terminated at that time, and the subject was debriefed. If the subject did not know the correct response-reinforcement contingency, the experiment was continued. The experimenter said, "I have to leave the room for a minute. When I return, we will begin the next period." The experimenter left the room to record the blink rate registered on the counter in the next room. Then the experimenter turned the counter back to zero and reentered the experimental room. The procedure for the other three periods was identical to that described for the first period.

If the subject had not correctly verbalized the reinforcement contingency after all four periods had been completed, a more extensive postexperimental interview was conducted. The experimenter asked, "What behavior do you think might have made the light come on? Did you think it was something you said? Did you think it was some nonverbal behavior? Do you think it might have been hand movements? Head movements? Smiling? Eye blinks?" A subject was classed as aware after the interview only if he mentioned blinks himself or had a very positive response when asked if the behavior was blinks. The subject was debriefed as to the purpose of the experiment and asked not to disclose any details to any of his classmates.

\section{RESULTS}

The first step in the treatment of the data was to eliminate from further analysis those subjects who were able to verbalize the correct response-reinforcement contingency. Six subjects had been classified as aware, 
four of them immediately after a reinforcement period and two during the postexperimental interview.

Data for the eight remaining unaware subjects were used in the statistical analysis. The mean blink rate for each 4-min period was computed; these results are shown in Figure 1. The mean blink rates for base periods were higher than the means for reinforcement periods. These data, then, show no indication at all of conditioning without awareness.

A two-factor analysis of variance was performed on the blink-rate data and is summarized in Figure 1. One factor analyzed in the analysis of variance was the Phase (A): Phase 1 consisted of $B_{1}$ and $R_{1}$, and Phase 2 consisted of $B_{2}$ and $R_{2}$. This factor was included in the analysis to determine if there was an upward or a downward trend in blink rate over time. The F value of 3.020 (df $=1 / 7)$ for the Phase factor was not statistically significant $(\mathrm{p}>.10)$, indicating no trend over time.

The second factor analyzed was the Experimental Condition (B): base vs. reinforcement periods. The $F$ value for this factor was $10.096(\mathrm{df}=1 / 7)$, which was significant at the .05 level. However, this $F$ 'value shows that the blink rate was significantly higher in the base periods than in reinforcement periods. Possible reasons for this surprising result are presented in the Discussion section of this paper.

The interaction of Phase by Experimental Condition (A by B) was also analyzed. An $F$ value of .712 (df $=1 / 7)$ was not statistically significant $(p>.20)$. Thus, it appears that there was no interaction between the two factors.

\section{DISCUSSION}

The hypothesis of the present study was confirmed: There was no conditioning of blink rate among subjects who were unaware of the response-reinforcement contingency. It seems likely that the subject in an experiment of this sort tries to find out what is going on and engages in testing various hypotheses. Dulany (1961), in an attempt to explain the evidence of conditioning without awareness, proposed that, in order for conditioning to occur, the subject must either be aware of the correct response-reinforcement contingency or must accept as correct some correlated hypothesis which leads him to make the desired responses without really being "aware." Another explanation of the conditioning without awareness effect was suggested by Levin (1961), who hypothesized that certain subjects classified as unaware may actually have been aware, but their awareness was not detected by the brief, insensitive interviews. The ideas of Dulany (1961) and Levin (1961) both seem reasonable; further exploration of hypotheses such as these may help to reconcile conflicting findings in the area of operant conditioning.

The present investigation indicated not only that no conditioning had occurred in the reinforcement periods, but also that the mean blink rate was actually higher in base than in reinforcement periods. This difference between base and reinforcement periods was statistically significant at the .05 level; therefore, the probability of this difference being due to chance is doubtful. Although this was an unanticipated finding, there is at least one possible explanation for its occurrence.
Ponder and Kennedy (1927) have proposed that a state of intense, but internally directed, mental activity is associated with a slower than normal blink rate. During the reinforcement periods, subjects were probably concentrating on determining which behavior made the light flash on. This increased concentration could have produced a subsequent decrease in the number of blinks. Barron (Note 2) similarly observed that the greater the cognitive load, the lower the blink rate. When a subject was not actively engaged in the task (base and rebase periods), he/she had a much higher blink rate. This suppression of blinks during cognitive activity is in agreement with studies conducted by Gregory (1952) and Poulton and Gregory (1952). Thus, the observed difference between eye-blink rate in base and reinforcement periods may be a function of the intensity of the subject's mental activity, or attention.

The data suggest that further research concerning awareness factors in nonverbal operant conditioning might benefit from taking into consideration the effects of certain cognitive factors on a subject's behavior. It might also be profitable for future research to examine awareness much more closely-to identify the exact moment of awareness, and to study what happens to the subject's responses immediately before and after the point when the subject becomes aware.

\section{REFERENCE NOTES}

1. Greenspoon, J. The effect of verbal and nonverbal stimuli on the frequency of members of two verbal response classes. Unpublished doctoral dissertation, Indiana University, 1951.

2. Barron, V. L. Blink rate as a function of cognitive complexity and emotional arousal. Unpublished master's thesis, Oklahoma State University, Stillwater, Oklahoma, 1973.

\section{REFERENCES}

DENike, L. D. The temporal relationship between awareness and performance in verbal conditioning. Journal of Experimental Psychology, 1964, 68, 521-529.

Dulany, D. E., JR. Hypotheses and habits in verbal "operant conditioning." Journal of Abnormal and Social Psychology, $1961,63,251-263$.

GrEenspoon, J. The reinforcing effects of two spoken sounds on the frequency of two responses. Americal Journal of Psychology, 1955, 68, 409-416.

GREGORY, R. L. Variations in blink rate during nonvisual tasks. Quarterly Journal of Experimental Psychology, 1952, 4, 165-169.

HALL, A. The origin and purpose of blinking. British Journal of Opthalmology, 1945, 29, 445-467.

Holland, M. K., \& Tarlow, G. Blinking and mental load. Psychological Reports, 1972, 31, 119-127.

KRASNER, L. Studies of the conditioning of verbal behavior. Psychological Bulletin, 1958, 55, 148-171.

LEvin, S. M. The effects of awareness on verbal conditioning. Journal of Experimental Psychology, 1961, 61, 67-75.

LUCKIESH, M. Reading and the rate of blinking. Journal of Experimental Psychology, 1947, 37, 266-288.

Ponder, E., \& Kennedy, W. E. On the act of blinking. Quarterly Journal of Experimental Psychology, 1927, 18, 89-110.

Poulton, E. C., \& Gregory, R. L. Blinking during visual tracking. Quarterly Journal of Experimental Psychology, 1952, 4, 57-65.

SiDowsKI, J. B. Influence of awareness and reinforcement on verbal conditioning. Journal of Experimental Psychology, 1954, 48, 355-360.

SPEnCE, K. W. Behavior theory and conditioning. New Haven: Yale University Press, 1956.

(Received for publication July 6, 1976.) 